
prepared States Government. Neither sponsored by the United States Goveres Atomic Energy the United States nor the United States Atomic nos any of Commiesion, not any of their employees, nos any of their contrictors, subcontractors, of their employees, their contructors, subcespress or implieá, or assumes any makes any warranty, express or for the aceuracy, comlecel linbility of responsibulity for the accir, apparatus, pleteness or usefulness of any information, ap paratus, product or process disclosed, or represents that its use

product or process distingtely owned rights.

\title{
A RADIATION MONITORING AND ALARM SYSTEM (AMOS II) FOR HABITABLE AREAS OF AN ACCELERATOR COMPLEX
}

Iouis M. Picinich*

and

$\operatorname{Car} 1 \mathrm{H}$. Distenfeld

\author{
Health Physics \& Safety Division \\ Brookhaven National Iaboratory \\ Upton, New York 11973
}

\begin{abstract}
Presented at the
Seventeenth Annual Meeting of the Health Physics Society Stardust Hotel, Ias Vegas, Nevada on 12-16 June 1972
\end{abstract}

\section{NOTICE}

This report was prepared as an account of work sponsored by the United states Government. Neither the United states nor the United States Atomic Energy Commission, nor any of their employees, nor any of their contractors, subcontractors, or their employees, makes any warranty, express or implied, or assumes any legal liability or responsibility for the accuracy, completeness or usefulness of any information, apparatus, product or process disclosed, or represents that its use would not infringe privately owned rights.

*

presently with Gruman corporation

S. Oyster Bay Road

Bethpage, New York 
AMOS II was developed as a radiation monitor for use in experimental areas of the Alternating Gradient Synchrotron (AGS). AGS pulse width variations, several microseconds to one second within standard repetition rates, dictate the use of an integrating type detector. The detector assembly consists of a polyethylene lined, ethylene filled integrating pulse discharge ionization chamber (IPDIC) and associated electronics. This assembly may be operated remotely from the AMOS II chassis. The alarm feature is field adjustable and consists of local audio and visual indicators plus a remote area coded alarm sent via radio telemetry to Health Physics Operations. Manual reset of this alarm initiates reminder alarms of 10 seconds duration and repetition periods inversely proportional to dose rates, as long as the alarm condition exists. Interconnected AMOS II units will allow simultaneous operation of alarm indicators without affecting the independent operation of the individual units. Local indication of prevaliing dose rates is accomplished using five dose rate bands to display possible area worktime limitations directly in days or weeks. A detector failure alarm is incorporated in the ratemeter function. Unique modular design was employed to facllitate interchangeability and ease of maintenance. 


\section{A. INTRODUCTION}

Alternating Gradient Synchrotron (AGS) East Experimental Area bulldings cover over three acres of floor space. The North Experimental Area beam Iines extend approximately $1 / 4 \mathrm{mile}$ from the target building. The target building is divided into two major longitudinal strips by the magnet enclosure shielding. Slow extracted beams eminate from the main biological shield and fan out to a variety of experimental apparatus. Secondary targeting offers even further area divisions (Fig. 1).

Crowding of individual beam Iines with multiple detectors and instrument laden house trailer complexes, coupled with the closeness of adjacent beam lines places a premium on avallable floor space (Fig. 2). A balance is required to minimize exposure risk with a minimum of shielding. The degree of risk can be reduced by carefully monitoring and adjusting exposure time where necessary. To permit flexible experimental operations and reduce exposure risk a comprehensive area monitoring system was initiated.

The area monitoring system (AMOS II) was designed to furnish a local indication of prevailing radiation dose rates and provide an alarm when a predetermined level has been reached. The presentable alarm expands the survelllance capabilities of Health Physics Operations personnel by uncovering excursions in the radiation levels. Alarm indicators consist of local audio-visual annunciators and an area-coded radio signal to Health Physics Operations. Determination of alarm point setting is accomplished through operational procedures and situation requirements confronting operational personnel. 
Local dose rate indicators provide more than information to attendant personnel; they attempt to inst1ll an omnlpresent Health Physles attitude to local occupants. Five radiation dose rate bands reflect worktime limitations as well as dose rate. Limits for dose rate indicators were established by the current exposure control philosophy of the AGS Health Physics Group.

\section{B. RADIATION ENVIRONMENT}

For instrumentation purposes, radiation exposure control will depend on the quality and intensity of the radiation field. Quality of a radiation field is determined by a complex mixture of particles and photons resulting from radiation transmission through the blological shield, scatter from the secondary experimental beams, and skyshine. Skyshine is deteryined by shielding that, for structural or economic reasons, has thicker sides than top. This radiation results from alr scattering and earth reflection. Overall radiation pattern is generally characterized by slowly increasing radiation intensities with an approach to the primary and secondary beam paths. The accelerator acts as a large diffused source.

Most of the radiation is produced after the accelerated particles have reached full energy and are directed to impinge on some targeting material. Targeting material will include beam stop and counters as well as targets situated within designated target areas. Targeting will occur with time periods varying from about 2 nanoseconds for certain external beam experiments to over 400 milliseconds for counter experiments. The possibility of nanosecond targeting periods is a prime factor to 
be considered in selecting the radiation detector. Nanosecond targeting periods, coupled w1th acceleration repetition periods of 2 seconds, dictate the use of an integrating type detector.

Some fraction of secondary beam particles are minimally lonizing and lose most of their energy through excitation and ionization rather than nuclear collision. This results in quality factors (Q) of 1 to 3.5 in secondary beam paths. Quality factors encountered on the experimental floor range from 1 to 10 , but average less than $5 .^{1}$

\section{c. AREA MONITORING SYSTEM}

AMOS II (FIg. 3) consists of three basic building bjocks; detector assembly, alarm, and ratemeter functions. Additionally, logic and turn-on safety is common to all and is separately considered. The detector assembly is the activator for both the alarm and ratemeter sections (Fig. 4).

\section{Detector Assemb1y}

Detector assembly, consisting of the detector and associated electronics, is external to the AMOS II chassis, (Fig.5). The electronics are within a chamber that is physically coupled to the detector.

The detector employed is a polyethylene lined, ethylene filled ion chamber. The integrating pulse discharge ion chamber (IPDIC) sums the lon current internally, producing an external pulse for each succeeding increment of dosage, nominally $0.5 \mathrm{mRad} .^{2}$

A high voltage supply and an amplifier comprise the detector assembly electronics (Fig. 6). High voltage for 
the IPDIC detector is produced by a push-pull D.C. to D.C. converter with voltage multiplication on the transformer secondary. 3 This high voltage supply is capable of producing 150 microamps at 1200 volts for the detector. The Darlington connected amplifier accomodates the IPDIC by furnishing a high input impedence (approximately 25 $\mathrm{K}$ ohms) while acting as a low impedence (100 ohms) line driver. The 1:1 pulse transformer inverts the negative detector pulse and superimposes it on the D.C. voltage supply line from the AMOS II. The detector pulse is decoupled from the D.C. supply line at the AMOS II chassis. Remote operation of the detector assembly is possible with a single coaxial cable whose limitation would be dependent on D.C. Iine losses., Separations of about 400 feet have been achieved with a theoretical limit of about 1000 feet. The aforementioned electronics allows the AMOS II to function as a purely digital device, insensitive to zero drift, gain changes, and range switching.

\section{General Instrument. Iogic}

The period of the detector pulses is the information used in the alarm and ratemeter subsections. Both subsections have independent methods for measuring time between detector pulses and they will be discussed in detail at a later time. Each subsection has basic groupings of counters, memories, and displays (Fig. 4). A transfer of information from the counters to their respective memories must be completed prior to the start of a 
new cycle by the counters. The pulse shaping and delay circuit (F1g. 4) performs the transfer of information by providing a pulse and a 100 microsecond delayed pulse, for each detector pulse, to be used by the memory devices and counters respectively. Obvious designations are reset pulse and delayed reset pulse, and they will be referred to as such for the remainder of the text. The detector pulse now consists of a reset and a delayed reset pulse that are transistor-transistor logic (TTL) compatible. The delayed reset pulse is generated by triggering two monostable multivibrators (SN74121) having equivalent timing cycles and looking at timing difference through a nand gate (FIg. 7).

\section{Alarm Section}

The adfustable alarm feature allows the Health Physics operational team to select an alarm point that is in keeping with proper exposure control. The alarm point is selected by a Bourn linear 10 turn "knobpot" mounted on the ratemeter faceplate (F1g. 8). Linear adjustment of dose rate is achieved by using the integrating amplifier to produce a constant charging current in the unijunction relaxation oscillator. ${ }^{4}$ Minimum clock speeds of 28 seconds per oscillator pulse are easily achieved, which is equivalent to $2.5 \mathrm{mrem} / \mathrm{hr}$ for a $0.5 \mathrm{mrad}$ IPDIC with a $Q$ of 5 (FIg.9). Two 4-b1t binary counters (SN7493) divide the oscillator output by 128 . The 8 th bit in the counters will be the alarm inhibitor. If this pulse has been achieved, prior to the next reset pulse, a nonalarm situa- 
tion will exist. In addition, the nonalarm condition will block the oscillator pulses from advancing the counting logic further through control of the nand gate.

The alarm inhibitor ( 8 th bit) is presented on the data input terminal of a bistable multivibrator ( $\frac{1}{2} S N 7474$ ) (FIg. 10). Input data is transferred to the output by "clocklng" the bistable with the reset pulse. Output of this bistable is cleared of an alarm condition through presentation of the alarm inibibtor signal on the "clear" input of the bistable. This allows the clearing of the alarm situation at the moment the 8 th b1t is achieved and eliminates the need to wait for a reset pulse to "clock" the bistable.

\section{a) Alarm silence}

This feature silences the alarm and stores the information that the alarm has been silenced as long as an alarm condition exists. The alarm sllenced bistable multivibrator ( $\frac{1}{2} S N 7474$ ) is activated by a momentary switch and presents a signal on the "clear" input of the alarm bistable. This signal prevents display of the alarm. Cancellation of the alarm silence signal occurs at the moment the 8 th bit is activated during any following cycle. In addition to a clearing of the alarm condition, the alarm sllence feature allows the monostable multivibrator (SN74121) to trigger with the next reset pulse. The monostable output pulse, of approximately 10 seconds duration, w1ll have a repetition rate which is inversely proportional to dose rate. This output will produce a reminder alarm for each detector pulse, if the manual alarm silence had been activated, and 
will remain until the 8 th bit has been activated. To eliminate false alarm during turn-on, a turn-on safety signal will clear the alarm and alarm silenced bistables.

\section{b) Alarm indicators}

The audio-visual alarm and radio alarm are separated from this point on. Audio-visual alarm indications are processed by a 4 input nand gate. Indications present on the inputs are alarm, alarm silenced reminder, and ar audio-visual alarm test. The output of the nand gate acts to drlve a relay through a transistor driver stage (Fig. 11). Relay contacts control the power for an audio card that produces a wobbling tone and a 4 " by 7 " lighted legend. Radio alarm indications are also processed by a second 4 input nand gate. Inputs include the alarm, alarm silenced reminder, radio alarm test, and a detector trouble indication that will be discussed at a later time. The output of the nand gate activates a relay whose contacts control the power for a lieathkit model GW21A radio. Modulation frequency of the radio will be the area designator used by the receiving equipment. Separate tes: switches were installed to allow testing of either alarm without extraneous noise or false telemetry signals.

\section{Ratemeter Section}

The ratemeter function of the AMOS II was designed in keeping with the current exposure control philosophy of the AGS Health Physies Group. Dose rate and worktime limitations are displayed directly on lighted color 
legends (Fig. 8). The basic counting circuitry is similar to that of the alarm feature. IPDIC sensitivity variations are normalized by the adjustable pulse oscillator (Fig. 12). The pulse oscillator is Identical to its counterpart in the alarm subsection. Output of the pulse oscillator is divided by three 4 bit binary counters. The binary counters w1ll perform the function of a 12 bit ring counter. Conditions in the 12 bit counter are presented to the memory input with some preprocessing by the NOR and INVERTER gates. The information in the counters 1s transferred to the memory by the reset pulse and about 100 microseconds later the delayed reset pulse will set the counters to zero. The last bit of the counters will be used as a detector trouble alarm. IPDIC repetition periods can be as long as eight hours without a detector trouble alarm for the $0.5 \mathrm{mrad}$ chamber. The substitution of a turn-on signal, to be clscussed later, for the 12 th bit (FIg. 12) will direct the display to the least significant legend indication at turn-on.

The four bits of information presented on the input of the memory by the ratemeter counting logic are transferred to the memory output by the reset pulse. A 4 bit bistable latch (SN7475) is used as the memory device (Fig. 13). An inverted output for each bit is available on the latch. Processing the 4 bits of in- 
formation by the display logic will provide the selection of one of the five lighted legends. Legend selection is carried out using a priority system with the least significant indication havIng the highest priority. Required inputs on the nand gate of the appropriate legend will be a bit Indication for that legend and no bit indication for any less significant legend. The most significant legend indication will occur if none of the other legends have a bit indication present. Dose rate band changes are easily accomplished through lamp legend changes and replacement of the memory card in the logic module with an appropriately designed card (Fig. 14).

\section{Turn-on Safety}

Turn-on characteristics of the IPDIC cause minor problems. Numerous pulses during initial chamber charging time must be disposed of and a safety signal must be developed to hold off the alarm bistable and give a safe ratemeter indication. Elimination of the turn-on safety signal is accomplished by the first detector pulse after the intitial 15 seconds of turn-on, whether it occurs seconds or hours later (Fig. 15). The turn-on safety signal is developed using a monostable multivibrator for the initial 15 seconds timing. The monostable output is present on the input of a bistable multivibrator that will be clocked by the 
delayed reset pulse. During initial charging of the IPDIC detector, the bistable will transfer the monostable output to its output, thereby providing a turn-on safety signal. The output of the bistable will be returned to zero by the first detector pulse after the monostable returns to its normal state. The inverted output of the monostable also "clocks" a second bistable that prevents the monostable from being triggered again as long as the power remains.

\section{CONSTRUCTION AND MAINTENANCE}

The AMOS II unit is assembled within a USAEC nuclear instrument module (NIM) bin using three 4-width modules. The modules are counting logic, alarm, and power supply. Arrangement of the three modules within the NIM bin is flexible to allow for situation conditioning of the individual unit.

Modular design was employed to facilitate maintenance. Replacement of a faulty logic card or module requires no special tools. This will increase the in-service time of the individual unit with only the modules presenting any possible logistic problems.

Field testing of completed units is in progress. 


\section{REFERENCES}

1. C.H.Distenfeld and A.M.Markoe, NUCIEAR INSTRUMENTS AND METHODS, 45, pp 181-189 (1966)

2. C.H.Distenfeld, W.Bishop, and J.Lamplough, NUCLEAR INSTRUMENTS AND METHODS, 49, pp 309-315 (1967)

3. S.Schwartz, Selected Semiconductor Circuits Handbook, J.Wlley and Sons, Inc. Chapter 9, and printing 1961

4. R.W.Fergus, ELECTRONICS DESIGN, 19, pp 106-107 (1970) 


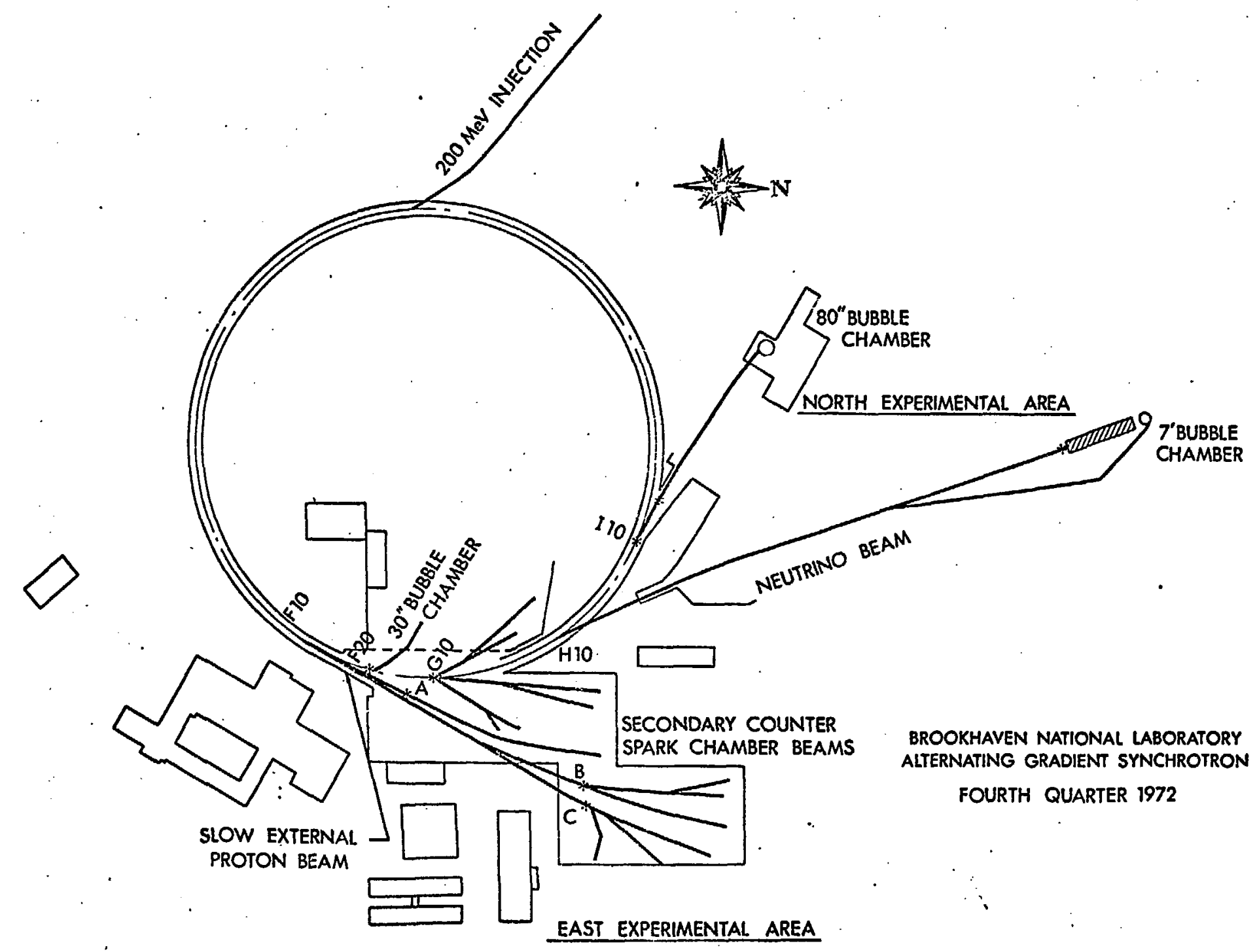

Figure 1. AGS Complex 


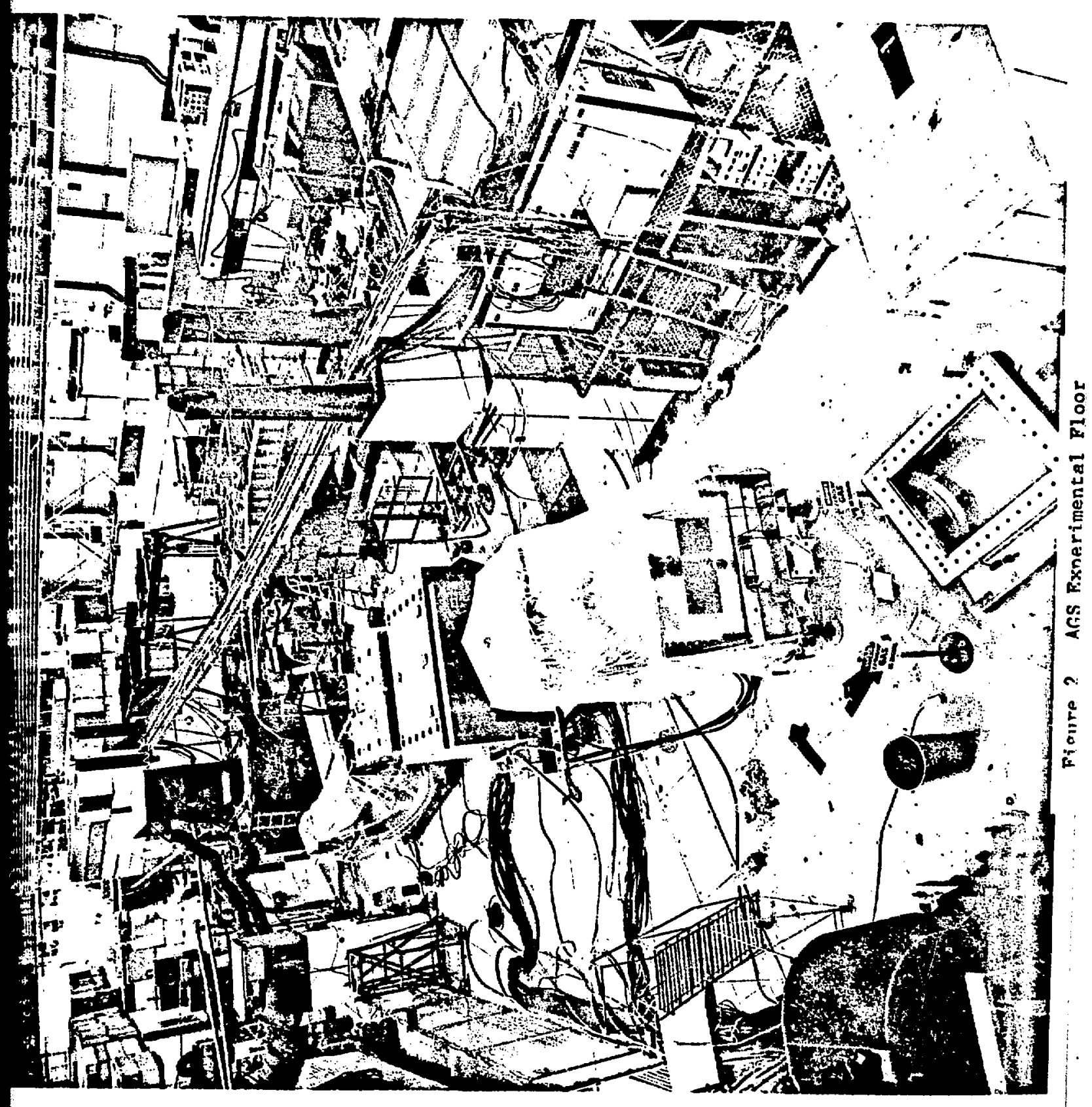




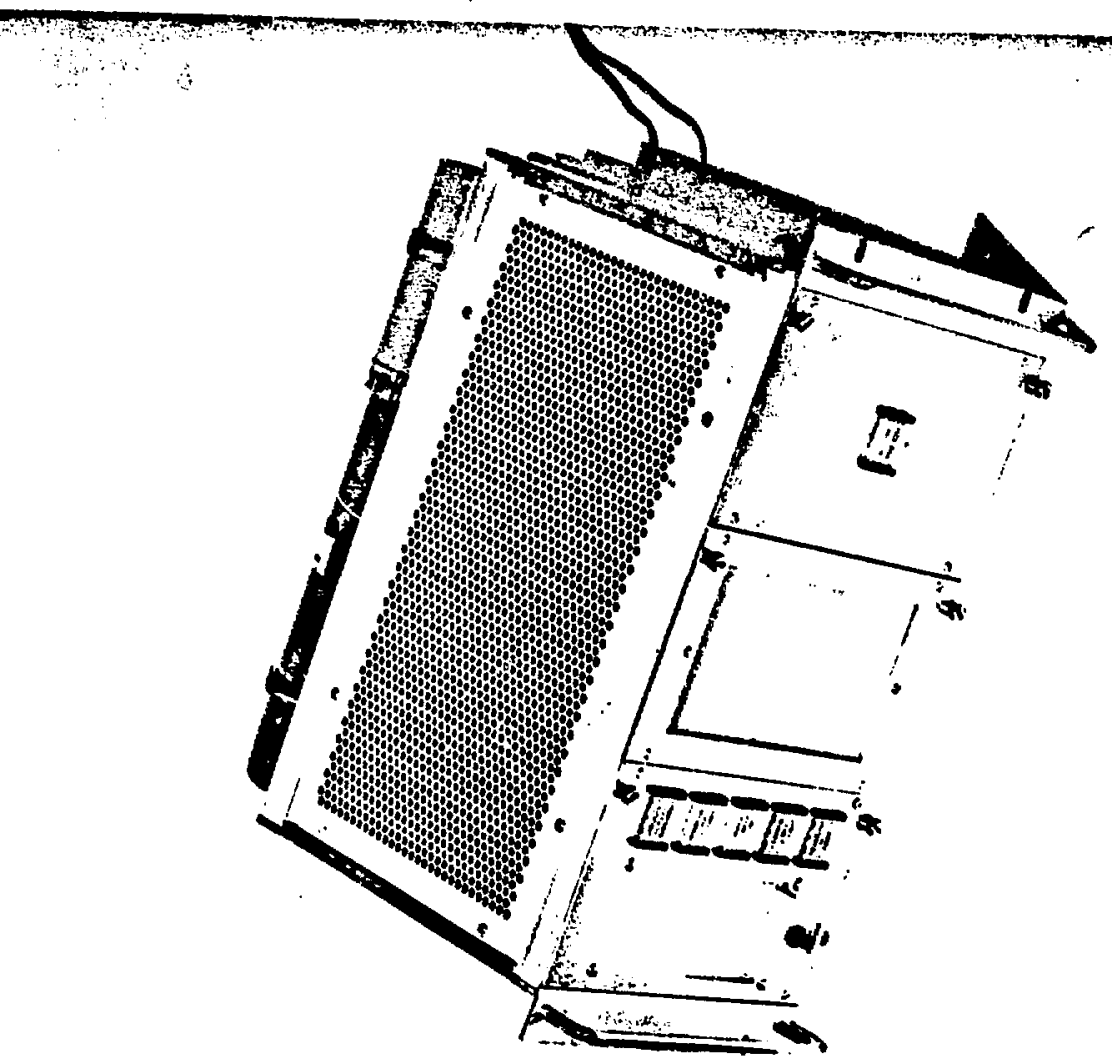

4
5
5
3
3

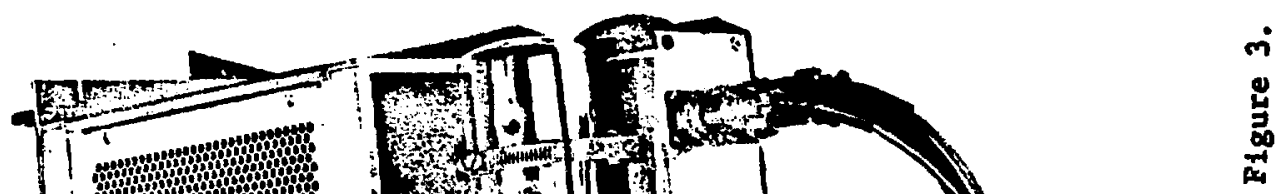




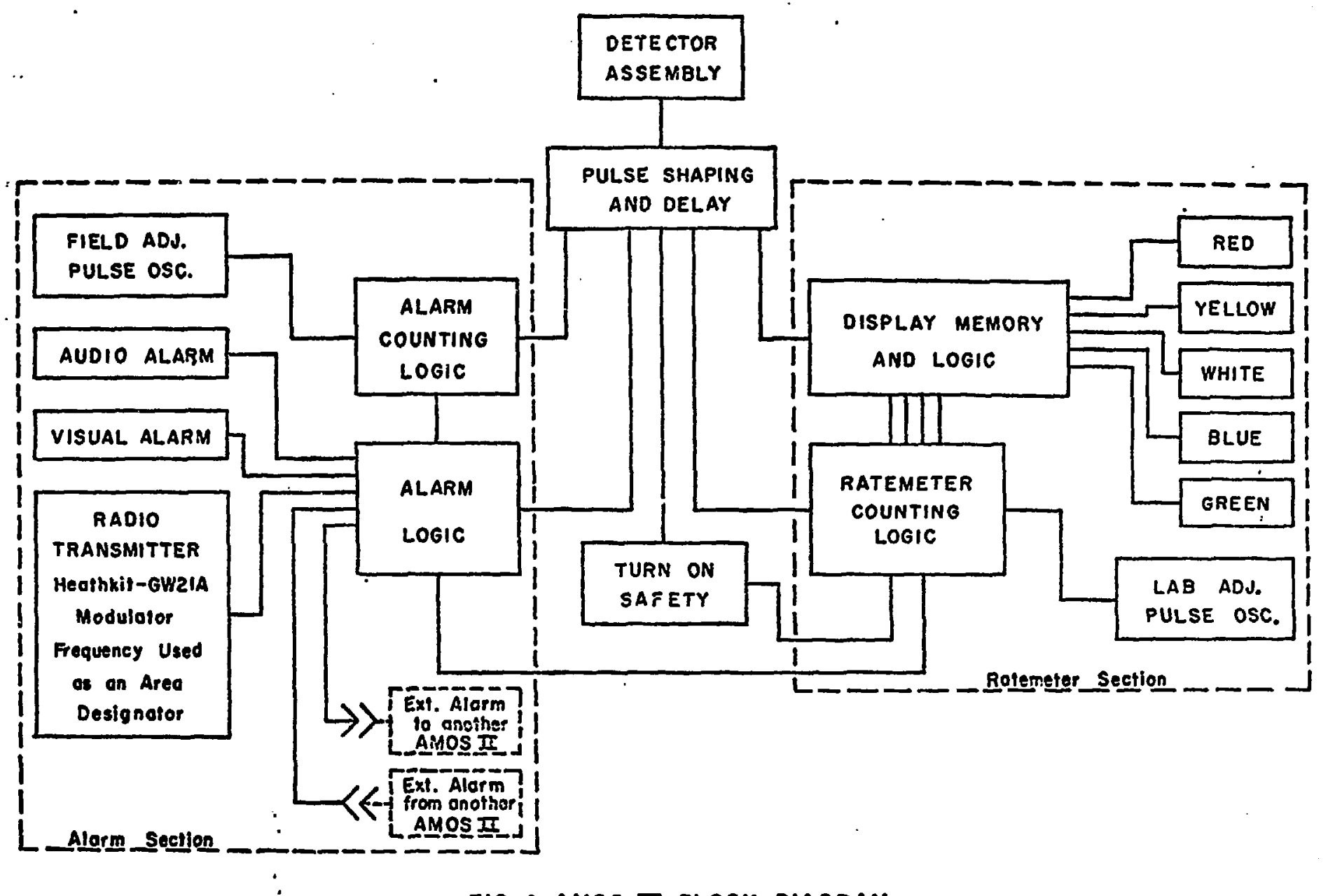

FIG. 4. AMOS II BLOCK DIAGRAM 


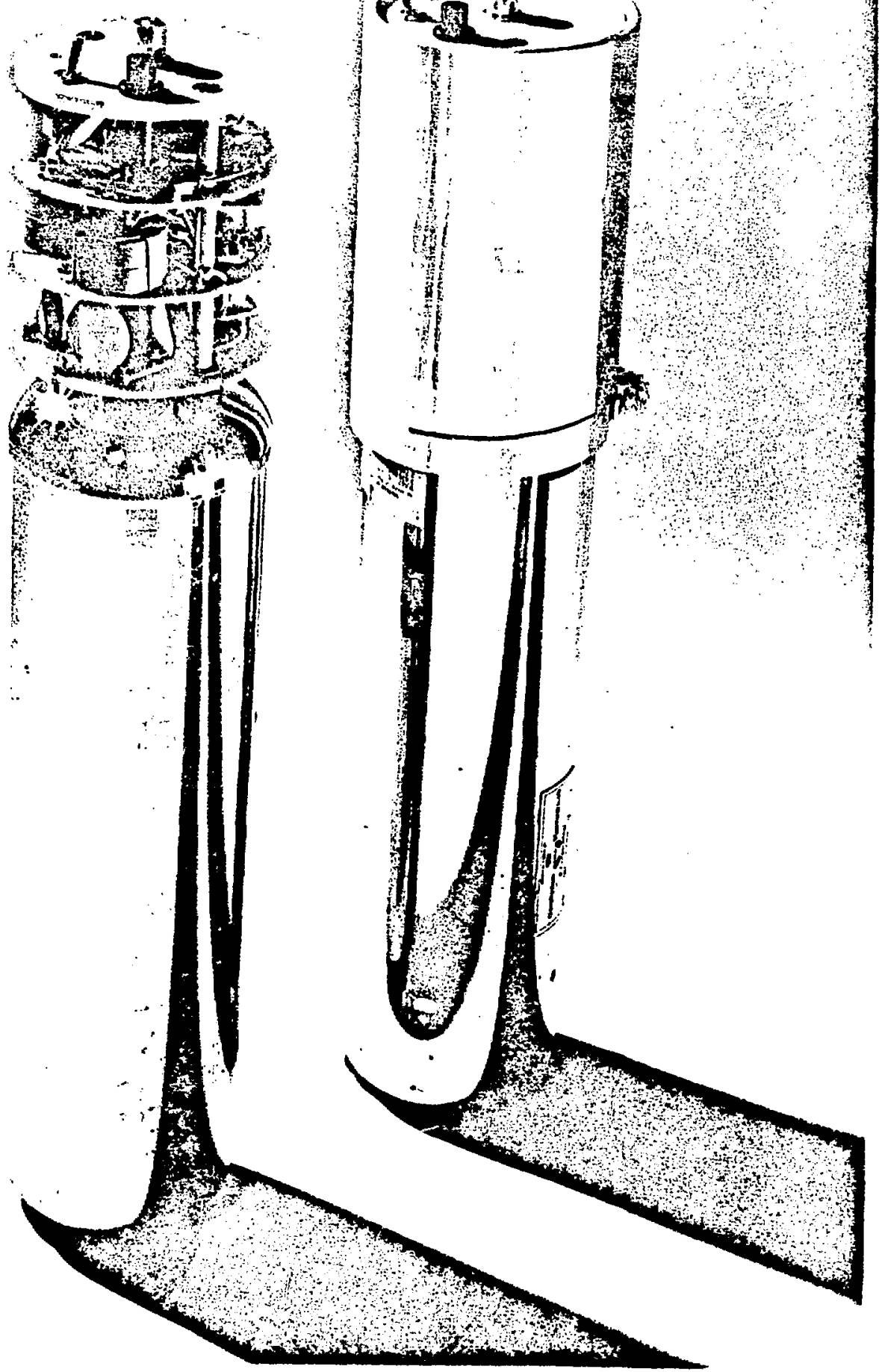

Figure 5. Detector Package 


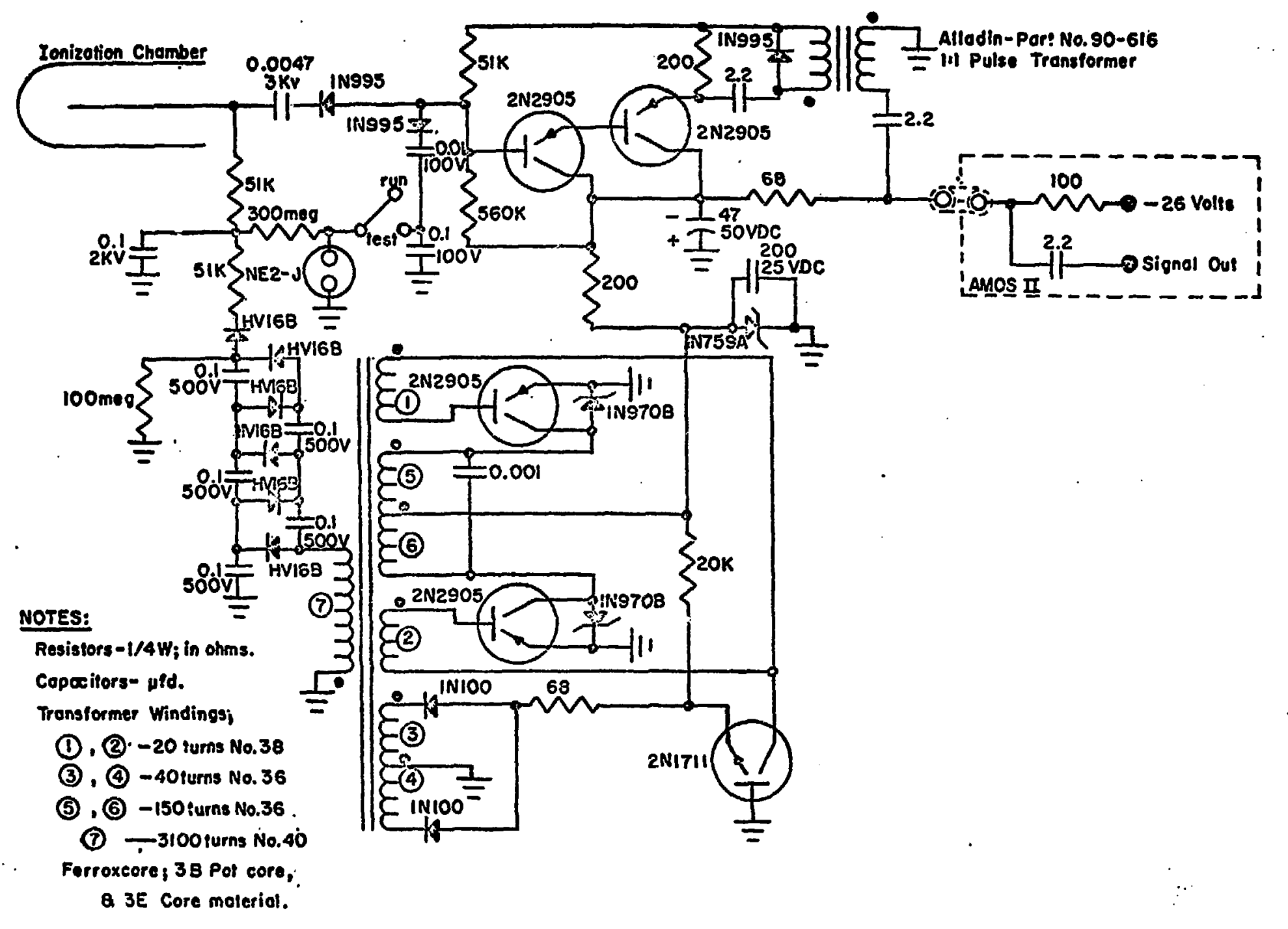

FIGURE 6. DETECTOR SCHEMATIC 


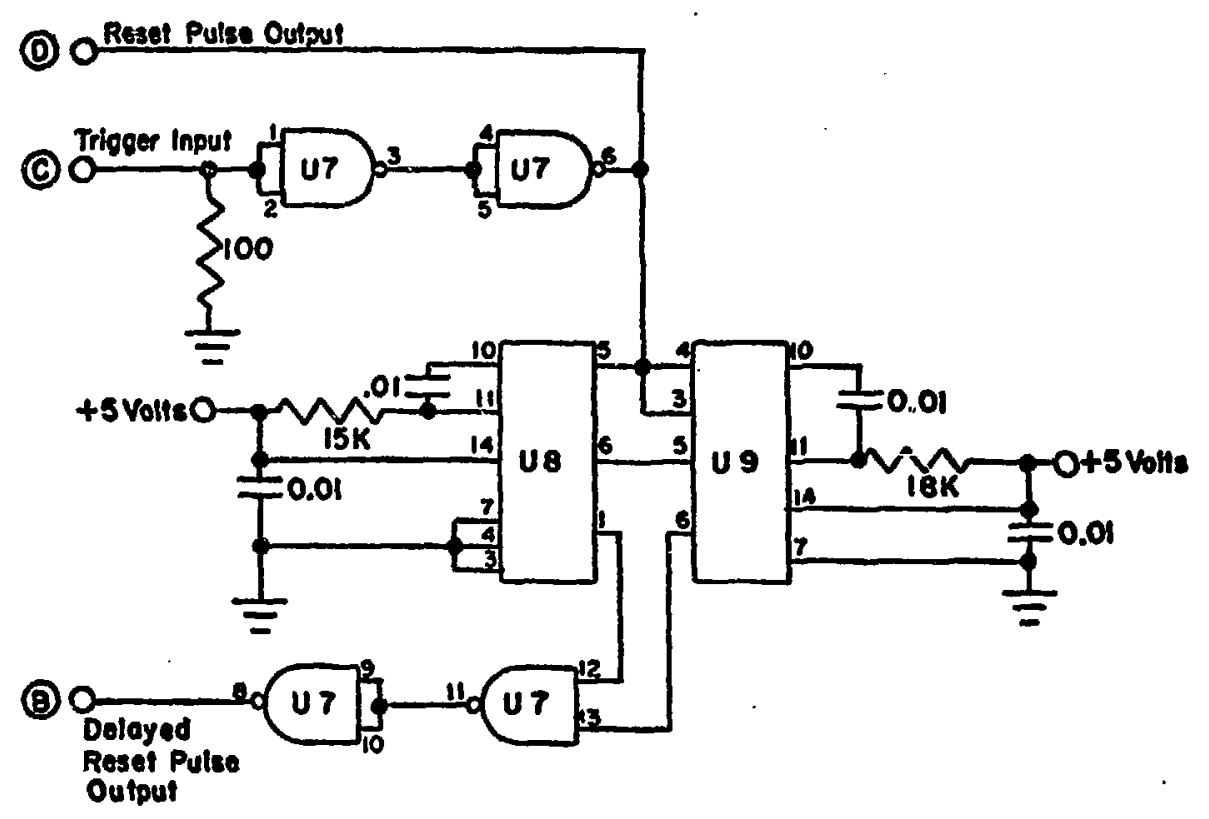

Notes

1. All resistors in ohms, 1/4W

2. All copacitors in. pfd.

3. Intarconnection - $\oplus$

4. U7-SN7400, U8 a 9-SN7412I

FIGURE 7. PULSE SHAPER a DELAY SCHEMATIC 


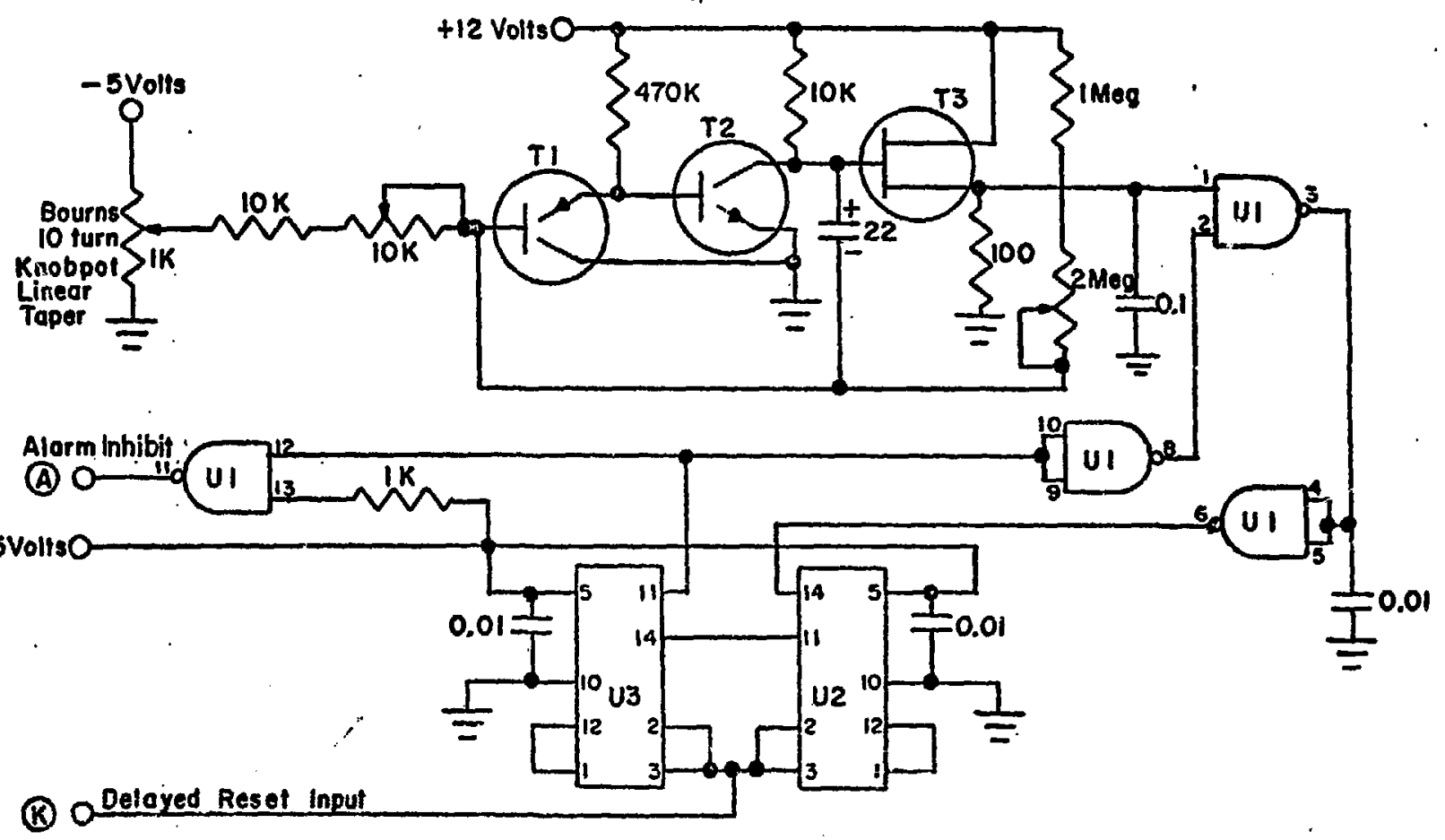

NOTES:

1. All resistors in ohms, $1 / 4 \mathrm{~W}$.

2. All copacitors in $\mu \mathrm{fd}$.

3. Inlerconnection .

4. TI-2N3906, T2-2N3904, T3-2N1671.

5. UI-SN7400, U2 a U3-SN 7493 .

FIGURE 9. ALARM COUNTING LOGIC SCHEMATIC 


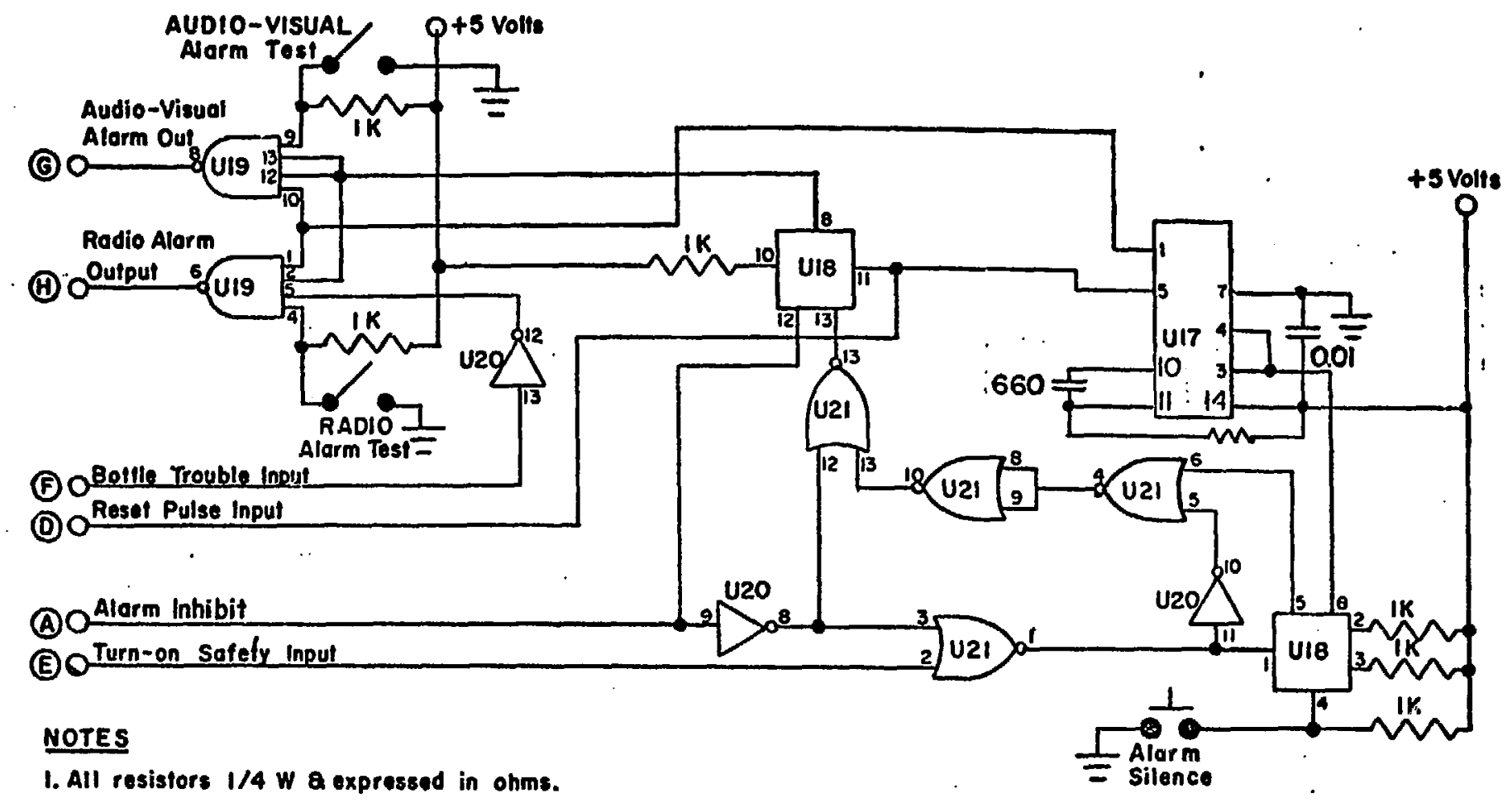

2All copocitors expressed in pfds.

3. $\circledast$ - interconnector.

4. U17-SN74121, U18-SN7474, U19-SN7420, U2O-SN7404, U2I-SN7402. 


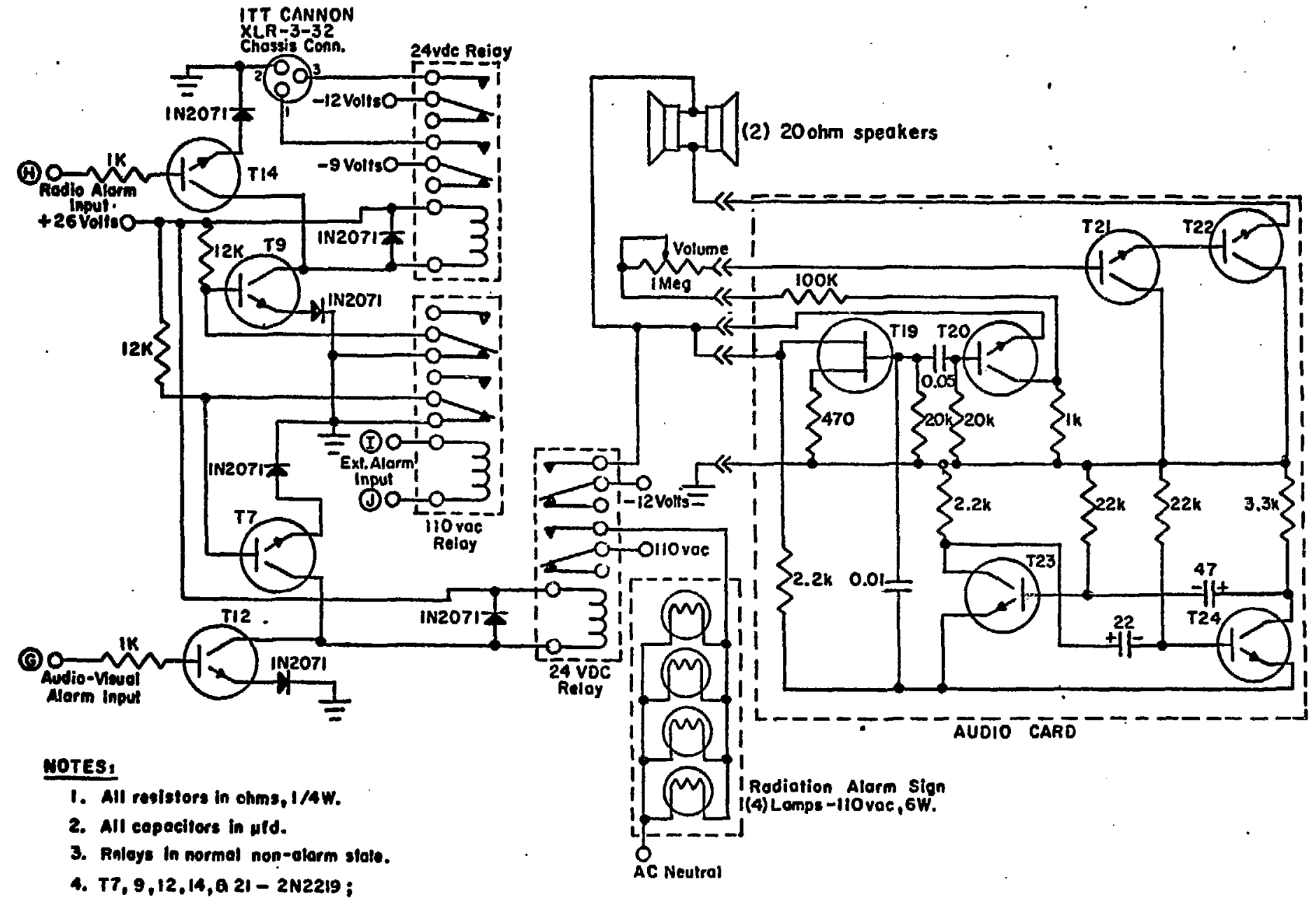

4. T7, 9,12,14,日 21 - 2N2219; T20, 23, 824-2NI7II; TIO-2NIGTIA.

3. O- Imierconnection. 


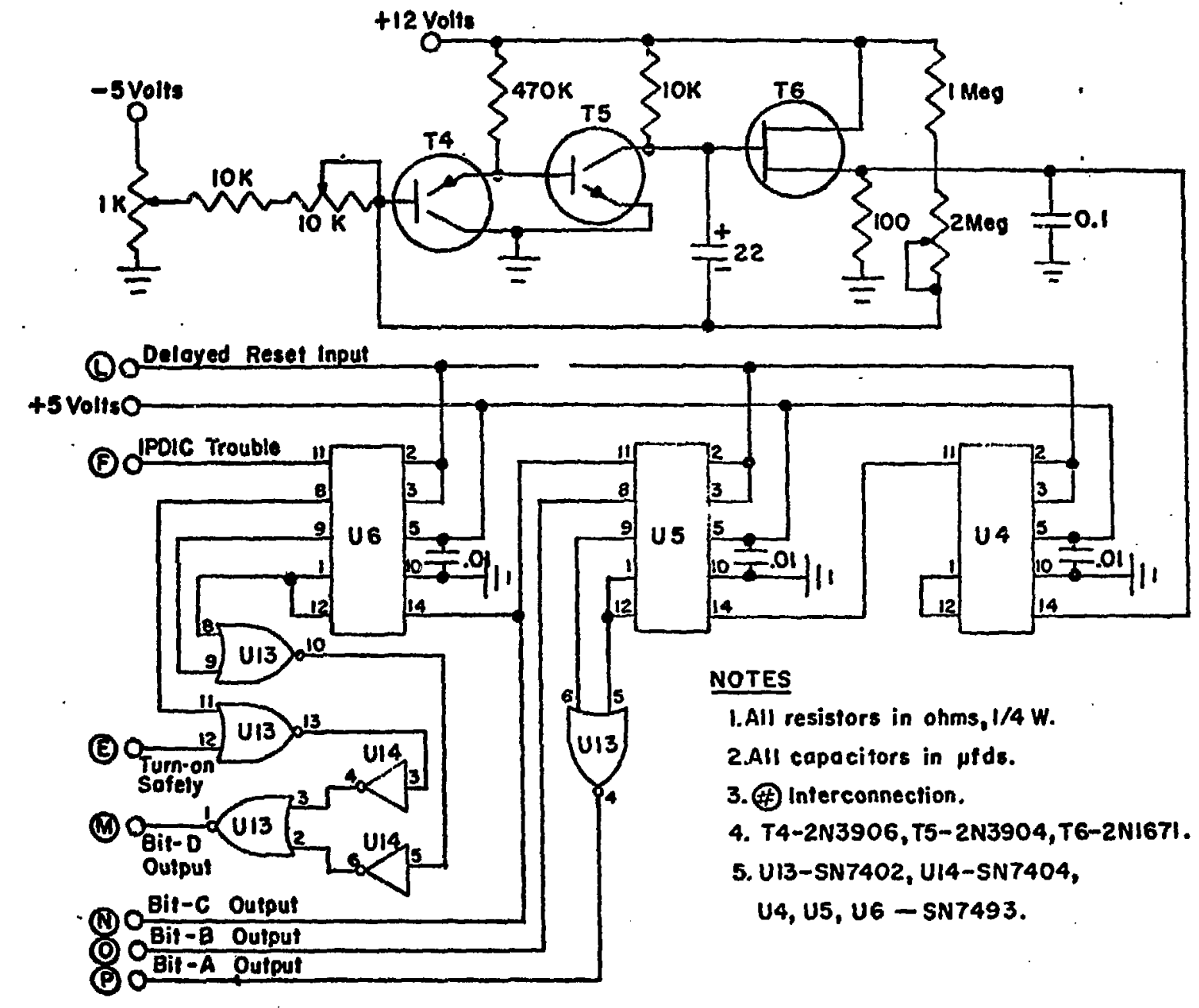

FIGURE 12. RATEMETER CLOCKING LOGIC SCHEMATIC 


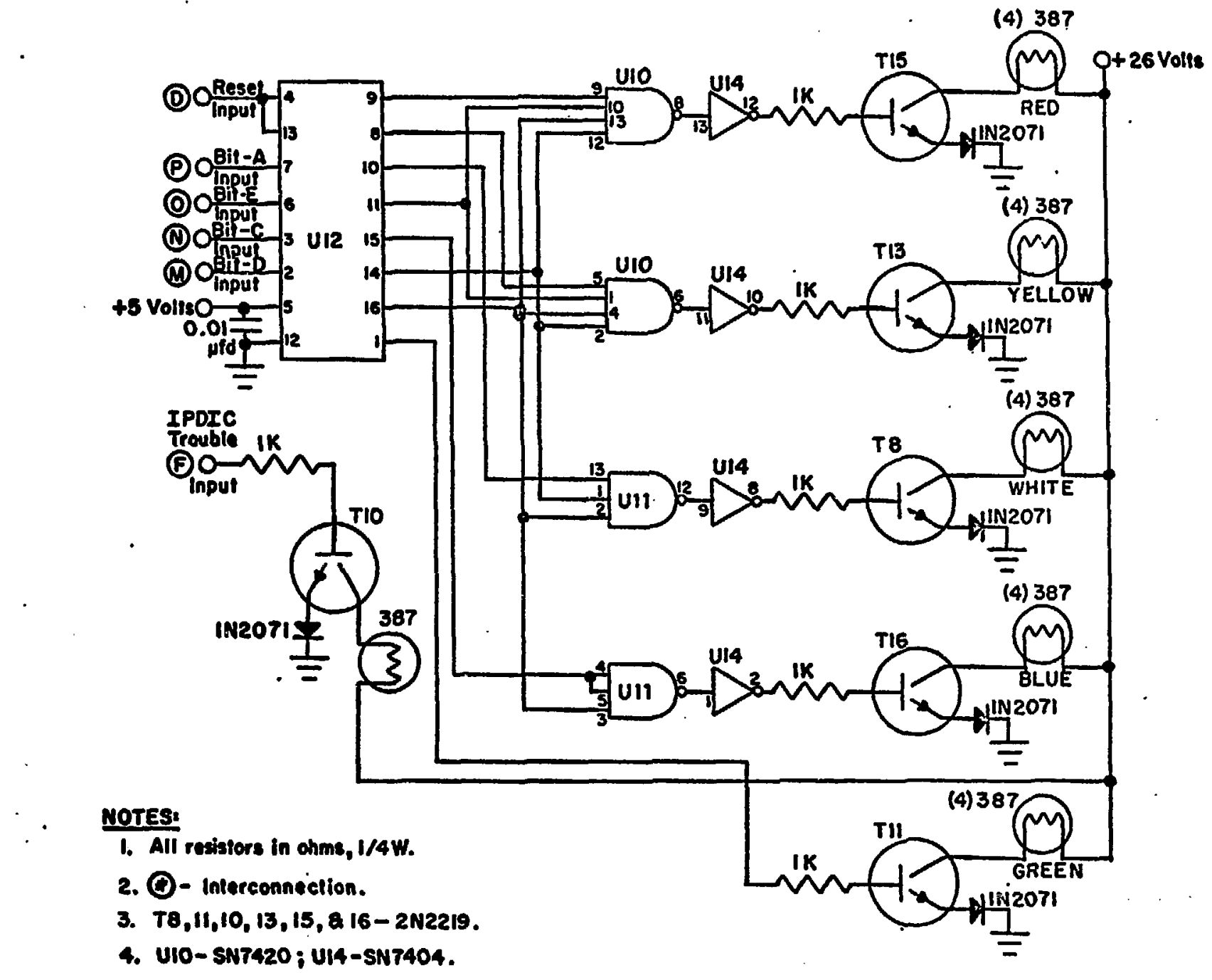

FIGURE 13. DISPLAY LOGIC AND DRIVER SGHEMATIC 

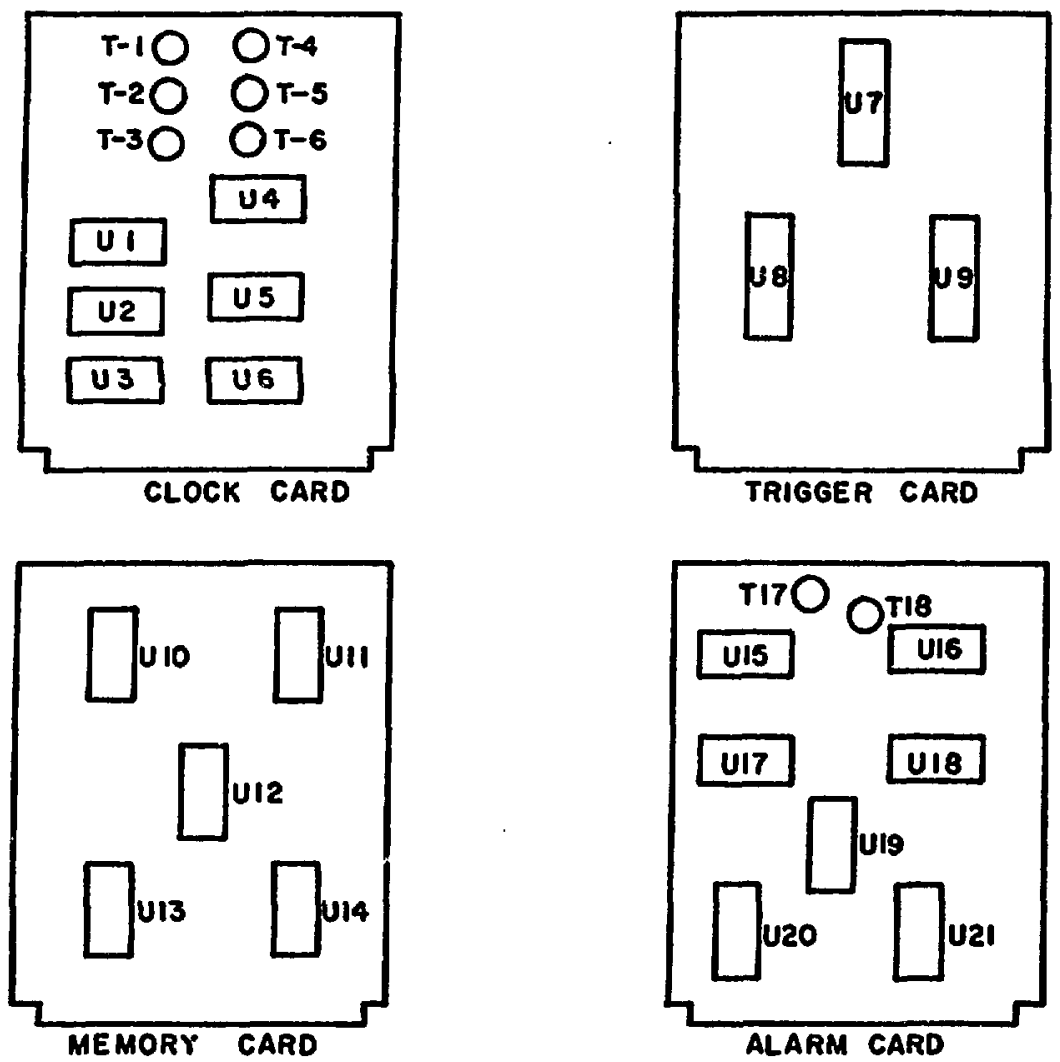

(rear)

Orr Ors Org

TRIGGER CARD

Orio Orı

Ori2 Or13 Orn

GLOCK CARO

\section{ALARM CARD}

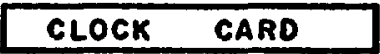

MENORY CARO

DRIVER CARO LOGIC MODULE (Card loyout- top)

FIGURE 14 TRANSISTOR A INTERGRATED CIRCUIT 


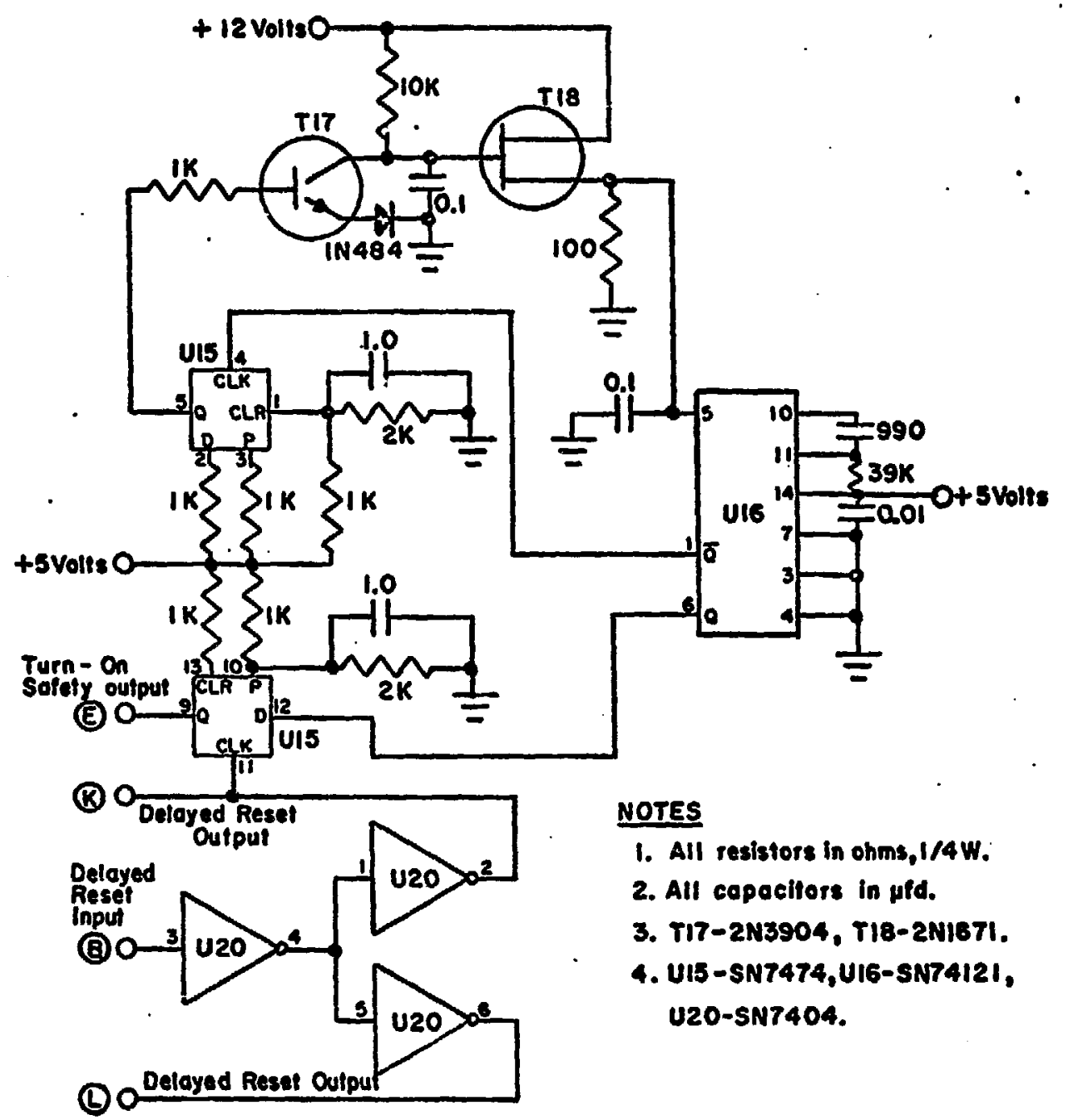

FIGURE 15. TURN-ON SAFETY SCHEMATIC 